\title{
Leprosy in Fiji
}

(Abstracted, with permission, from the Medical and Health Report of Fiji for 1934).

The following is a report of the Central Leper Hospital, Makogai. (See illustrations facing page 125.)

After a number of years during which the Gilberts and Ellices have made inadequate efforts to care for their lepers, these are being transported to the leper island of Makogai early in 1935. New Zealand, Fiji, Tongo; Gilbert and Ellice Islands, Western Samoa, Niue and the Cook Islands co-operate in the island of Makogai in the Fiji group, where lepers receive treatment and care unsurpassed in the world, and where there is a measure of contentment impossible to understand by one who has not seen it. These participating groups are entitled to the highest credit for their foresight in co-operating to handle a situation which no one of them can do so well alone.

In spite of this fact, there is little accurate knowledge of the extent of leprosy in the South Pacific. No survey has ever been made in any group by men skilful in diagnosis and with adequate scientific equipment. On a recent hurried survey of Rotuma among a population of 2,500, Dr. V. W. T. McGusty by visual and manual inspection sorted out enough lepers with those already in Makogai to amount to over 2 per cent. of the population. About half of these are considered to be infectious. In the Solomon Islands on the savage island of Malaita, 100 miles long and 20 to 30 miles wide, which has been little explored, a survey was made from which a 1 per cent. infection with leprosy was estimated in a population of 44,000 . In this group there are one to two Government medical officers and two Native Medical Practitioners. The finances of the Colony offer no possible hope of attempting to deal with the situation. As has been said there are no adequate facts concerning leprosy in the South Pacific. Probably also there is no place in the world where the etiology and epidemiology of leprosy can be so well studied as in certain small atoll islands in the South Pacific, which are almost isolated from communications so that the whole factors of the problem can be seen without extraneous complications. Here fresh cases are presenting themselves each year since the eighteen-eighties.

An outline for a leper survey of the Pacific is on file by the former 
Medical Officer, who had six years experience at Makogai Leper Island, and who has inspected leper conditions in several other countries.

Statistics.-The eighty-nine admissions for the year include sixtyfive cases from Fiji itself, sixteen from Rotuma, seven from Samoa and one from Niue Island. The nationalities are indicated in Table I, which also shows the varying types of disease among the admissions. A little over 50 per cent. of the cases were of the neural type; only two showed extreme deformities, and no case had reached the advanced cutaneous stage. This appears to represent a definite improvement, and is probably largely due to the growing realisation among practitioners and natives alike of the importance of early diagnosis and treatment.

\section{TABLE I-AdMissions 1934.}

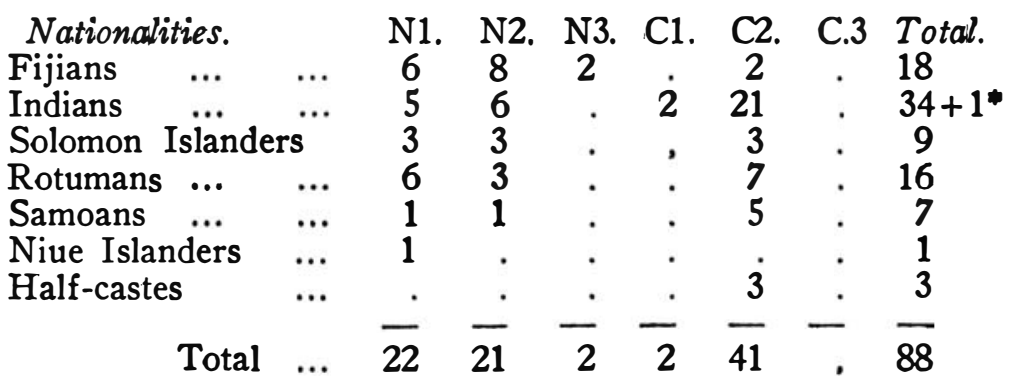

* One Indian admitted and later discharged as a non-leper.

Deaths.-Of the seventeen deaths, there were nine among the Fijians, three of Solomon Islanders and Indians, and one each from among the Cook and Niue Islanders.

Death rates for the past five years are as follows:-

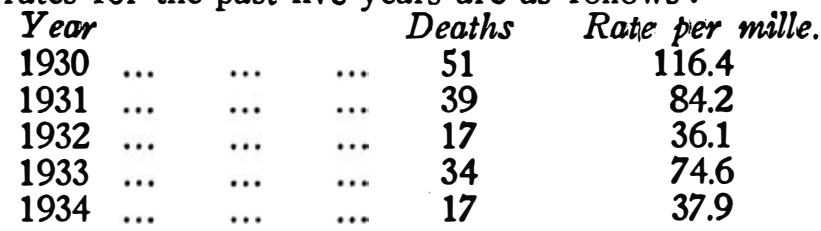

This appears to show a fairly steady improvement, particularly in view of the fact that it is the advanced cases who are left each year while the earlier cases tend to be discharged or, in the case of Indians, repatriated.

Causes of death are shown in the following list :-

Exhaustion from Leprosy ... $\quad \ldots \quad \ldots \quad$... 4

Nephritis (including Uræmia) $\ldots . \quad \ldots \quad 3$

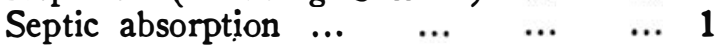

Tuberculosis-

(General 2, Pulmonary 1, Abdominal 1) 4

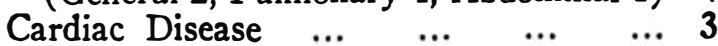

$\begin{array}{llllll}\text { Cardiac Disease } & \ldots & \ldots & \ldots & \ldots & 3 \\ \text { Pneumonia } \ldots & \ldots & \ldots & \ldots & \ldots & 1\end{array}$

$\begin{array}{llllll}\text { Hæmatemesis } & \ldots & \ldots & \ldots & \ldots & 1\end{array}$

It will be seen that eight of the deaths (including those due to exhaustion, nephritis and septic absorption) may be fairly attributed to leprosy and nine to causes apparently unconnected with leprosy. 
Deaths in Relation to Type.

$\begin{array}{lllllll}\text { Neural-1 } & \ldots & \ldots & \ldots & \ldots & \ldots & 1 \\ \text { Neural-2 } & \ldots & \ldots & \ldots & \ldots & \ldots & 3 \\ \text { Neural-3 } & \ldots & \ldots & \ldots & \ldots & \ldots & 4 \\ \text { Cutaneous-1 } & \ldots & \ldots & \ldots & \ldots & 0 \\ \text { Cutaneous-2 } & \ldots & \ldots & \ldots & \ldots & 3 \\ \text { Cutaneous-3 } & \ldots & \ldots & \ldots & \ldots & 6\end{array}$

The foregoing list, however, showing deaths in relation to the stage of leprosy, indicates that this cannot be taken entirely at its face value. It is hardly conceivable, for example, that leprosy played no part in the causation of death in each of the nine advanced and moderately advanced cutaneous or of the four advanced neural cases. The probability is that in every case the resistance to other morbid conditions is lowered by leprotic infection, although of course the converse may also be true, the disease causing death being the primary condition which had lowered the resistance to leprosy when encountered.

\section{TABLE II.}

Nationalities. N1. N2. N3. C1. C2. C3. Total. $\begin{array}{llllllllll}\text { Fijians } & \ldots & \ldots & 14 & 45 & 15 & 6 & 39 & 23 & 142\end{array}$

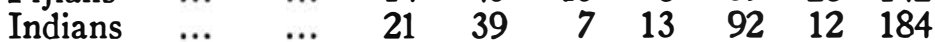

\begin{tabular}{|c|c|c|c|c|c|c|c|c|c|}
\hline \multicolumn{3}{|c|}{ Solomon Islanders } & 12 & 11 & & 4 & & & 16 \\
\hline Rotumans & $\ldots$ & $\ldots$ & . & 3 & . & . & 4 & 2 & 9 \\
\hline Chinese & $\ldots$ & $\ldots$ & & & . & . & 6 & 3 & 9 \\
\hline Samoans & $\ldots$ & $\ldots$ & 1 & 2 & & & 13 & 1 & 17 \\
\hline Tongans & $\ldots$ & $\ldots$ & 1 & 2 & 1 & 2 & 1 & . & 7 \\
\hline Cook Islan & ders & $\ldots$ & 3 & 10 & 4 & $\overline{1}$ & 10 & & 28 \\
\hline Niue Islan & ders & $\ldots$ & 1 & 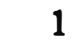 & & $\cdot$ & r & 1 & 3 \\
\hline Maoris & $\ldots$ & $\ldots$ & . & & 1 & $\cdot$ & & ${ }^{\circ}$ & 1 \\
\hline Half-caste & & $\ldots$ & & 2 & & & 7 & $\cdot$ & 9 \\
\hline Europeans & $\ldots$ & $\ldots$ & 1 & . & 1 & r & 1 & $\cdot$ & 3 \\
\hline & Tota & $\ldots$ & 54 & 115 & 29 & 26 & 189 & 45 & 458 \\
\hline $\mathbf{P}$ & age & $\ldots$ & 11.8 & 25.1 & 6.3 & 5.6 & 41.2 & 9.8 & \\
\hline
\end{tabular}

Table II is of interest in showing the proportion of neural to cutaneous cases in the various nationalities. The only three with sufficient numbers for percentages to have comparative value are the Fijians, Indians and Solomon Islanders who give respectively $\mathbf{5 2 . 1}$ per cent., 36.4 per cent., and 50 per cent. of neural cases. This ratio is similar to that reported in previous years and as will be shown later, the Indians, in spite of their higher proportion of cutaneous cases, continue to give a much higher rate of improvement. It may be pointed out in passing that although the Fijians have a lower proportion of cutaneous cases than the Indians, 16.2 per cent. of their cases are in the advanced cutaneous stage as contrasted with 6.5 per cent. of the Indians. That is to say that the Indians, in spite of their apparently heavier infection, show a much higher rate of improvement, and a much lower proportion of cases advancing to the extreme condition. The explanation of this undoubted fact, supported as it is by records over a number of years, is probably not a simple one. The Fijian accepts his condition philosophically 
and more or less fatalistically, settles down to the life here and is content to be separated from his immediate family provided he be with others of his own race. The Indian on the other hand actively resents the need, forced upon him by his disease, of isolation from his family, and is in most cases willing to seize every chance and carry out any method suggested to him of improving his condition so that he may be discharged and rejoin his own relatives. This psychical factor is in my opinion of the utmost importance. Evidence regarding possible differences in racial susceptibility is contradictory or at least inconclusive. It may well be that an investigation on scientific lines of the respective diets of the Indians and Fijians here would be of considerable value in explaining the differences observed and in pointing the way to further improvement.

Treatment.-It is impossible to overemphasise the value of general hygienic treatment coupled with treatment of concurrent diseases. If one had to make a choice between such general health measures and specific lepra therapy, one would unhesitatingly choose the former. Fresh air, suitable dietary, cleanliness and graduated exercise are indispensible as a preliminary to specific treatment and it is probably from these factors, which are more under the control of the patients themselves, rather than in specific treatment, which is more easily regulated, that the Indian reaps his advantage. Patients are encouraged to lead an open air life : sports are arranged and prizes donated from the Comfort Fund; the utmost use is made of patients with regard to Public Works and the produce of their garden is bought for Hospital use.

Specific treatment has continued on the lines recorded in the last Annual Report, the standard treatment being weekly intramuscular injections of iodised ( 0.5 per cent.) chaulmoogra oil. According to Cole, "Chaulmoogra-group oils to which 0.5 per cent. iodine is added become so viscous that difficulty is experienced in attempting to use them by injection." This is true unless the oil is kept at a suitably high temperature. Immediately prior to injection the freshly iodised oil is heated for an hour on a water bath and is then poured into a large warmed and sterile thermos flask. Small quantities are poured as required throughout the period of injections into glass beakers standing in basins of hot water. If this method be followed there should be no further difficulty owing to viscosity, the product being comparable with the iodised ethyl esters. The patients agree that this is the least painful injection they have so far received and they much prefer it to the iodised esters to which they formerly paid the same tribute. Results are at least as good as those of previous years. There have been only two cases of abscess formation resulting from nearly 12,000 injections, both occurring in patients suffering from furunculosis, and apart from these there have been no signs of non-absorption. The high temperature of the injected oil probably plays no small part in assisting absorption.

Chaulmoogra oil by mouth to the limit of tolerance, varying with different patients, has been continued. The addition of 0.5 per cent. iodine which was at one time thought to be an improvement, has been discontinued, patients finding it after a while less well tolerated than the pure oil.

Mercurochrome, as recommended by Muir, has proved a 
useful addition to the small list of drugs such as antimony and sodium tartrate, ephedrine and dilester (E.E. of calophyllum bigator), utilised for the control of reaction.

Minor experiments have been carried out with certain of the aniline dyes as suggested by Ryrie, but with inconclusive and somewhat contradictory results. They are being continued into the New Year, however, on a larger scale and results will be assessed with care.

Only thirty operations, in almost every case of a minor character, have been required during the year.

Results of Treatment.-The appended table of statistics shows twenty-two patients actually discharged during the year. To this figure should be added a further seven cases who were "Boarded out " in December, but had to await transport until the beginning of the year. This gives twenty-nine cases passed by the Medical Discharge Board during the year as having been free from active disease for at least two years. In the following table these cases are classified according to nationality and type of Disease.

\section{TABLE III.-Discharges 1934.}

Nationalities. N1. N2. N3. C1. C2. C3. Total

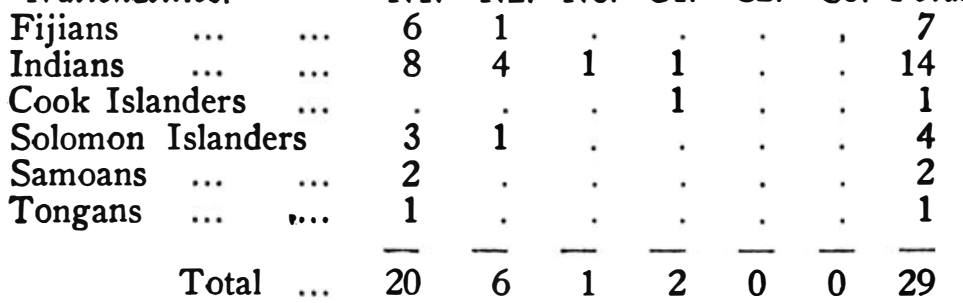

Table IV shows four hundred and fifty-eight patients examined at the end of the year arranged according to nationality and type of leprosy. A number of patients who had only been admitted three or four months previously were not included.

The combination of quiescent and arrested cases, which gives a total of the "inactive" cases in each stage is a much better criterion of real progress than the classification "improved," which is a vague term dependent on the personal predilections of the examiner. Early cutaneous cases show nearly as high a proportion of "total improvement" as early neural cases, but this is mainly due to the lesser degrees of improvement. Thus cutaneous 1 cases show only 38.5 per cent. in the inactive condition as contrasted with 64.8 per cent. of the early neural cases, while actual discharges are seen in Table III to have been ten times as many in early nerve as in early cutaneous cases.

Sex Differences.-The usual preponderance of male over female patients is illustrated in Table V, which gives three hundred and twenty-seven males to one hundred and thirty-one females. On the whole the females are less advanced, with a larger proportion of neural cases, and this fact is reflected in their slightly better response to treatment. Thus of the three hundred and twenty-seven male patients, 38.5 per cent. were neural in type and 64.2 per cent. showed "improvement", while of the one hundred and thirty-one females, 
54.9 per cent. were neural and 71.7 per cent. were "improved." Progress therefore depends much more on the stage of the disease than on any differences due to sex, in spite of the fact that the more active and less restricted life of the men would tend to give them a better chance.

Produce.-The patients' gardens have done very well during the year, and the open-air exercise entailed in their cultivation is regarded as an important adjunct to specific treatment. About one hundred and seventy-five tons of cassava, bananas, \&c., have been bought for Hospital use at $£ 4$ per ton-a valuable encouragement to the patients as well as providing a more nutritious diet than bought rice. Many of the patients keep their own ducks and fowls and there is quite a traffic in these, particularly at such times as Christmas.

The Hospital fowl-yard has been improved by the importation of more Silver Wyandottes, in order to prevent deterioration due to inbreeding. Nearly 12,000 eggs and 300 fowls have been supplied to the Hospital, a splendid addition to the normal dietary of the patients. Great credit to due to the native sisters who, under the direction of the Reverend Mother, are responsible for the care of the poultry.

Milk, meat and soap have been produced at Nasau for use at the Hospital and I have asked the Lay Superintendent to report on Farm Produce, Stores, \&c. Details will therefore be found in an Appendix.

Chaulmoogra Trees.-The Chaulmoogra trees originally planted in 1926, but badly damaged by the storms of 1930 and 1931, have largely recovered and are now doing well. About a hundred of the Hydnocarpus wightiana trees are now bearing fruit, but so far there has been no sign of fruit on the Hydnocarpus anthelmintica trees, which have moreover a less healthy appearance. About three pints of oil, which appears to be of excellent quality, have so far been prepared, and specimens have gone forward for analysis. 